\title{
O CONCEITO DE NATUREZA NA FILOSOFIA DE LUDWIG FeUERBACH
}

\author{
Eduardo Ferreira Chagas ${ }^{1}$
}

\begin{abstract}
Resumo: O presente artigo pretende destacar a tese de que a natureza, conforme Feuerbach, é um existente autônomo e independente e possui primazia ante o espírito. Para ele, a natureza material, que existe, em sua diferencialidade qualitativa, independente do pensar, é, diante do espírito, o original, o fundamento não deduzível, imediato, não criado de toda existência real, que existe e consiste por si mesmo. Feuerbach opóe a natureza ao espírito, pois ele a entende não como um puro outro, que só por meio do espírito foi posto como natureza, mas, como o primeiro, a realidade objetiva, material, a qual existe fora do entendimento e é dada ao homem por meio de seus sentidos como fundamento e essência de sua vida. Trata-se, portanto, primeiro daquela essência (luz, ar água, fogo, plantas, animais etc.), sem a qual o homem não pode nem ser pensado nem existir. A natureza é, para Feuerbach, a pluralidade de todos os objetos e essências que realmente são. Sob essa condição, é possível conceber a natureza como a garantia da exterioridade mesma, como que um existente fora de nós, que nada sabe de si e é em si e por si mesmo; por conseguinte, ela não deve ser vista como aquilo que ela não é, isto é, nem como divina, nem como humana. A natureza sempre existiu, quer dizer, ela existe por si e tem seu sentido apenas em si mesma; ela é ela mesma, ou seja, nenhuma essência mística, pois, por trás dela, năo se esconde nenhum absoluto, nada humano, nada divino, transcendental ou ideal.
\end{abstract}

Palavras-chave: Conceito de Natureza em Feuerbach. Crítica ao Teísmo e ao Idealismo. Feuerbach.

\section{INTRODUÇÃo}

Partindo de uma interpretation imanente dos escritos principais de Ludwig Andreas Feuerbach (1804-1872), o presente trabalho remete

\footnotetext{
${ }^{1}$ Doutor em Filosofia pela Universität von Kassel e Pós-Doutor em Filosofia pela Universität Munster. Professor efetivo (associado) do Curso de Filosofia e do Programa de Pós-Graduaçáo em Filosofia da Universidade Federal do Ceará (UFC), Fortaleza, CE - Brasil. Professor colaborador do Programa de Pós-Graduação em Educação Brasileira da FACED - UFC. (D) https://orcid.org/0000-0003-19576117. E-mail: ef.chagas@uol.com.br.
}

https://doi.org/10.1590/0101-3173.2021.v44n3.04.p51

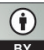

This is an open-access article distributed under the terms of the Creative Commons Attribution License. 
a um aspecto central de sua filosofia, que fora, infelizmente, até hoje insuficientemente investigado, a saber, a sua acepção de natureza. Tem-se, aqui, em primeiro plano, a seguinte hipótese: a reflexion de Feuerbach, que se refere, no âmbito de sua argumentation, à autonomia da natureza (Autonomie der Natur) (ou seja, à natureza autônoma, autárquica, independente, que existe em-si e por si mesma, independentemente da consciência humana) e que procura proporcionar-lhe valor, é para ser entendida como corretivo à religião e à filosofia especulativa, para poder fazer, assim, simultaneamente, fronteiras a tais direçóes.

No que tange à pesquisa acerca do entendimento da natureza, tal como concebida por Feuerbach, devem ser mencionados, sobretudo, os trabalhos de Werner Schuffenhauer, Peter Cornehl, Ursula Reitemeyer, Alfred Schmidt, I. M. Jessin, Joachim Höppner, Francesco Tomasoni, Heinz Hüsser, assim como as contribuiçôes (em forma de artigos) de Regina Steindl, Gerd Haensch, Gisela Schrötter, Theodor Münz e Hermann Ley. Enquanto Reitemeyer e Cornehl (mas também Münz e Haensch) se limitam, em seus escritos, ao conceito de natureza do jovem Feuerbach nos anos 30 do séc. XIX, priincipalmente às obras Dissertação sobre a Razão (Dissertatio über die Vernunft), Pensamentos sobre a Morte e a Imortalidade (Gedanken über Tod und Unsterblichkeit), Apresentação, Desenvolvimento e Crítica da Filosofia Leibniziana (Darstellung, Entwiclung und Kritik der Leibnizschen Philosophie) e História da Filosofia Moderna (Geschichte der neueren Philosophie), nas quais Feuerbach visa a superar, ainda no âmbito de suas concepçóes panteístas, o dualismo entre espírito e natureza, Schmidt e Jessin, do mesmo modo que Höppner, se ocupam, em seus trabalhos, com o significado da concepção de natureza de Feuerbach para Marx, assim como com a crítica de Marx a Feuerbach, e, por isso, recorrem, de preferência, aos seus escritos intermediários, os quais compreendem os anos de 1839-1842, a saber, Critica à Filosofia Hegeliana (Kritik der Hegelschen Philosophie), Teses Provisórias (Vorläufige Thesen), Necessidade de uma Mudança (Notwendigkeit einer Veränderung) e Princípios da Filosofia do Futuro (Grundsätze der Philosophie der Zukunft). Já Tomasoni, Ley e Hüsser tratam o conceito de natureza de Feuerbach nos seus escritos de maturidade, particularmente a partir de 1846 (SOUZA, 1998, p. 55-93).

Uma vez que todos os trabalhos mencionados consistem em uma apresentação isolada, fragmentada, ou seja, se restringem a um determinado ponto da concepção de natureza em Feuerbach, permanecendo o desenvolvimento e as alteraçóes dessa concepçáo ainda a ser investigados, tem 
este trabalho por objeto, primeiramente, o conceito de natureza de Feuerbach na sua totalidade e deve apresentar, nesse sentido, uma análise mais detalhada e sistemática do mesmo. Embora a concepção de natureza de Feuerbach só se deixe revelar, de forma mais clara, na sua "última fase", ela deve, não obstante, ser tratada como um todo, como resultado do conjunto de sua filosofia. Precisamente por isso, o presente texto tem por tarefa mostrar como Feuerbach desenvolveu o seu conceito de natureza dos anos 30 do séc. XIX até os escritos de maturidade e quais funktion e relevância pertencem a ele, no interior de sua filosofia.

\section{O Conceito de natureza em Feuerbach}

O conceito de natureza em Feuerbach constitui uma das questóes mais difíceis de sua filosofia e não é, por conseguinte, fácil de ser explorado; ele fora tratado, no âmbito das pesquisas sobre a filosofia feuerbachiana, quase exclusivamente em conexão com sua antropologia e sua crítica filosófica à religião e, em segundo lugar, reduzido à natureza do homem. Tendo em vista, precisamente, a deficiência das pesquisas até então realizadas, pretendo aqui averiguar o seguinte: que significado atribui Feuerbach, de fato, à natureza em si, se ele próprio se referiu, em seus escritos juvenis, apenas em geral à natureza, se se ocupou primeiro, em sua crítica à religião, tão-somente com o gênero humano e só posteriormente refletiu assistematicamente sobre a natureza? A princípio, poder-se-ia, então, perguntar: por que se interessa Feuerbach, como crítico da religiáo, em geral pela natureza? O que ele entende por natureza e o que ela significa para ele? Existe para ele uma natureza independente, fora do entendimento ou da natureza humana? Como se apresenta para ele a ilação homem-natureza, ou melhor, como o homem se relaciona com ela? Que lugar destina Feuerbach ao homem no interior da natureza? Como compreende ele a diferença entre o homem e o animal?

Partindo dessas questóes, irei aqui desenvolver e explicar o conceito de natureza em Feuerbach. Conquanto ele não tenha empreendido, infelizmente, uma formulação completa de sua concepção de natureza como um todo, isto é, não tenha deixado nenhuma filosofia da natureza explícita e acabada e também não tenha redigido nenhum escrito pormenorizado e sistematizado acerca da natureza, há, todavia, em sua obra, em diferentes passagens, uma abundância de aforismos, epigramas, definitionen e reflexóes filosóficas sobre a natureza. Assim, o conceito de natureza de Feuerbach foi desdobrado, em 
sua obra, na verdade apenas de maneira fragmentada, mas ele está, apesar disso, no centro de sua filosofia. O desenvolvimento e a transformação desse conceito perpassam, de certa maneira, como fio condutor, a totalidade da obra de Feuerbach, abrem um caminho para entendermos a sua filosofia como crítica ao teísmo (Theismus) e ao idealismo (Idealismus) e nos permitem tratála sistematicamente.

Neste artigo, tornar-se-á evidente que a ausência de uma sistematização, ou seja, de uma precisão ou de uma clara posição, no que se refere ao conceito de natureza em Feuerbach, se encontra fundamentada nisto: que a pretensão principal de sua filosofia é, como acima aludido, a crítica ao teísmo (sobretudo ao Cristianismo) e ao idealismo (especialmente à filosofia de Hegel), os quais são deficitários em relação à natureza, visto que eles não só abandonaram, mas especialmente menosprezaram a consideração da natureza. A falta, em Feuerbach, de uma reflexion decidida, explicitamente formulada sobre a natureza, pode, consequentemente, ser entendida, em princípio, como expressáo da ausência de uma tematização da natureza no teísmo e no idealismo em geral. Acerca dessa problemática, deve ser aqui estabelecida, inicialmente, a tese de que a natureza (Natur) em Feuerbach possui o primado frente ao espírito; ela é a primeira estrutura da existência e frente a ela se póe o entendimento como algo "secundário". Afirma Feuerbach (1967b, p. 105):

\begin{abstract}
Natureza [...] é tudo o que tu vês e não provém das mãos e dos pensamentos humanos. Ou, se quisermos penetrar na anatomia da natureza, ela é o cerne ou a essência dos seres e das coisas, cujos fenômenos, exteriorizaçóes ou efeitos, nos quais exatamente sua essência e existência se revelam e dos quais constam, não têm seu fundamento em pensamentos, intenções ou decisóes do querer, mas em forças ou causas astronômicas, cósmicas, [...] químicas, físicas, fisiológicas ou orgânicas.
\end{abstract}

No decorrer deste artigo, mostrar-se-á, pois, que, para Feuerbach, a natureza material, que existe, em sua diferencialidade qualitativa, fora e independentemente do pensar, é, frente ao espírito, o primeiro, o originário. A natureza, entendida como totalidade, como unidade orgânica, como harmonia de causas e efeitos, como pressuposto necessário para todos os objetos, fenômenos e criaturas, plantas e animais, inclusive para a natureza humana, fornece a Feuerbach o fundamento de sua crítica ao teísmo e ao idealismo; isto é, a natureza é o motivo de sua konfrontation com ambos, os quais desconhecem completamente a autonomia (Selbständigkeit), a autarquia (Autarkie) e a independência (Unabhängigkeit) da natureza, porque 
eles a concebem ou meramente como obra de um criador, ou como puro desdobramento e exteriorização da atividade do espírito. Em ambos os sistemas, foi a natureza tratada, portanto, não como um existente autárquico, independente, autônomo, mas deduzida apenas como uma grandeza dependente e inconsistente em si mesma. Assim compreendido, mediante um entendimento da natureza que se baseia nas características imanentes a ela - imediaticidade, autarquia, autonomia, regularidade universal (lei), impessoalidade e lógica, necessidade, dinamicidade -, Feuerbach formulará não só sua crítica ao teísmo e ao idealismo, como também alicerçará, na maturidade, sua própria ética.

Embora não haja, em Feuerbach, nenhuma concepção uniforme, homogênea e inequívoca da natureza, é-nos permitido constatar o seguinte: a referência à autarquia, à autonomia da natureza (Selbständigkeit der Natur) é o fundamento da crítica, ou melhor, o cerne da reaktion e konfrontation feuerbachiana ao teísmo e ao idealismo, que se desdobra em três diferentes fases de desenvolvimento: 1. como aproximação crítica ao panteísmo (identidade da natureza com Deus), 2. como recusa direta à teologia cristã e à filosofia hegeliana (a natureza como criação de Deus ou como deduktion do espírito) e 3. como crítica parcial à religião da natureza (antropomorfização ou personificação da natureza). Por isso, concentrar-me-ei, inicialmente, nos escritos de juventude dos anos 20 e 30 do século XIX, particularmente, a Dissertação sobre a Razão (Dissertation über die Vernunft ou De Ratione una, universali und infinita) (1828), os Pensamentos sobre a Morte e a Imortalidade (Gedanken über Tod und Unsterblichkeit) (1830), a Introdução à Logica e Metafísica (Einleitung in die Logik und Metaphysik) (1829-30), a História da Filosofia Moderna (Geschichte der neueren Philosophie) (1835-36) e a Apresentação, Desenvolvimento e Crítica da Filosofia Leibniziana (Darstellung, Entwiclung und Kritik der Leibnizschen Philosophie) (1837), nos quais Feuerbach trata a natureza de um ponto de vista panteísta.

Partindo de um panteísmo que se orienta sobretudo em Giordano Bruno, Jakob Böhme e Baruch Spinoza, ele tenta, já nesse período, restabelecer, frente à depreciação da natureza pela religião cristã e em oposição à identidade formal entre pensar e ser postulada pela filosofia hegeliana, uma reconciliação entre ser e pensar, uma unidade entre natureza (matéria) e Deus (espírito). No panteísmo ele vê, na verdade, não só tal reconciliação, mas também a superação do subjetivismo e da personificação de Deus (de um Deus transcendente), e, por isso, o panteísmo sinaliza para ele a soluçáo para 
os problemas filosóficos fundamentais. Nem Cristianismo, nem idealismo podem solucionar adequadamente tais problemas, porque eles não têm formulado uma relação adequada para a natureza. Assim como no idealismo, em geral, também no Cristianismo, o eu domina o mundo e se considera como o único ser espiritual que existe; nele é redimida apenas a pessoa, não a natureza, o mundo; centralizado no eu, na pessoa, o Cristianismo é apenas uma religião, na qual se revela o abandono completo da natureza, pois nele foi consumada a separação entre a natureza e Deus. Enquanto, para o teísmo, o espírito é imaterial, não sensível, transcendente, e Deus uma essência absoluta que existe para si, personificada, extramundana ou estranha ao mundo, admite, ao contrário, o panteísmo, abstraindo aqui as suas diferentes tradiçóes, Deus imerso na natureza; com isso, ele destaca a unidade do mundo com Deus (com o espírito). Se a característica essencial do teísmo é, por conseguinte, o isolamento de uma essência do pensamento, abstraída da natureza pelo homem, existe, ao contrário, no panteísmo, Deus no interior da natureza.

\section{A recepçáo crítica de Feuerbach ao panteísmo}

Numa clara oposição à teologia monoteísta-cristá, que faz da essência humana a origem de Deus e da natureza um produto da creatio ex nihilo, concebe o místico Jakob Böhme a natureza (a matéria) como inerente a Deus, inseparável dele. E Spinoza identifica Deus com a natureza mesma (deus sive natura) e a esclarece como a gênese do homem; mediante a natureza (a substância divina) ele supera, então, a contradição de Descartes entre matéria (res extensa) e espírito (res cogitans). A aproximaçáo de Feuerbach a essas formas de panteísmo, concebidas por Böhme e Spinoza, foi, contudo, superada posteriormente, nos anos de 1836-37, sobretudo em seu escrito contra Spinoza. Afirma Feuerbach (1967b, p. 104):

Entendo em geral sob natureza certamente como Spinoza, náo um ser como o Deus sobrenatural, que existe e age com vontade e razáo, mas que atua somente conforme a necessidade de sua natureza; mas ela náo é para mim, como é para Spinoza, um Deus, ou seja, um ser ao mesmo tempo sobrenatural, transcendente, deduzido, misterioso, simples, e sim um ser múltiplo, [...] real, perceptível com todos os sentidos.

Para Feuerbach (1969a, p. 445), no pensamento de Spinoza, 
Deus e natureza são sinônimos, equivalentes, pois o poder, pelo qual as coisas singulares e, por conseguinte, o homem obtêm o seu ser, é mesmo o poder de Deus ou da natureza. O poder do homem é, por conseguinte, uma parte do poder infinito de Deus ou da natureza.

Ou, ainda mais claro: "[...] só a força e o poder da natureza é a força e o poder de Deus mesmo, pois a potência do efeito, o poder de uma coisa é sua essência mesmo, então a essência da natureza é a essência de Deus mesmo.” (FEUERBACH, 1969a, p. 447-448). Em oposição ao panteísmo, no qual natureza e Deus foram concebidos como idênticos e a matéria tratada tãosomente como um atributo de Deus (o atributo natural-divino da extensio), Feuerbach exige a diferença entre natureza e Deus (aut deus aut natura). Isso significa: ele não quer esclarecer nem a natureza como algo divino, nem Deus como algo imanente à natureza, mas, pelo contrário, a natureza como autônoma, sem Deus. Sob a premissa de que Deus se manifesta na natureza, o panteísmo venera a natureza, diviniza o real, o que existe materialmente; por isso, ele é, na verdade, uma negation da teologia, mas baseado ainda em posiçôes teológicas.

Essa censura de Feuerbach se dirige a todos aqueles que veem na natureza uma expressão de Deus ou a encarnação de uma ideia. Em verdade, teísmo e panteísmo são, para ele, mundos extremos, invertidos: no teísmo, a diferença entre espírito e natureza é absolutizada, porque o homem diviniza aqui apenas a si mesmo; já no panteísmo, a natureza foi, ao contrário, adorada, pois aqui o homem projeta na natureza sua própria essência. Para evitar tais extremos e contradiçôes, Feuerbach vê, em princípio, na Doutrina das Mônadas de Leibniz, uma alternativa para a unidade entre o espírito e a matéria. Pertence à mônada espiritual a forma, contudo, ela contém simultaneamente em si também a matéria, que é a sua representação obscura. Todavia, enquanto Leibniz considera a matéria meramente como uma representação escura, confusa, Feuerbach a reconhece, pelo contrário, como o vínculo positivo que liga o interior com o exterior, as mônadas, reciprocamente.

\section{A crítica de Feuerbach ao cristianismo e À filosofia hegeliana como POSIÇÓES CONTRÁRIAS À NATUREZA}

Seguindo a primazia da natureza, a qual tem seu fundamento em si mesma, e sob a consideração de sua autarquia, autonomia, como objeção 
(Einwand) ao teísmo e ao idealismo, mostrar-se-á, na segunda parte deste artigo, o conceito de natureza de Feuerbach em conexão com sua crítica ao Cristianismo e, ao mesmo tempo, em discussão com a filosofia hegeliana, isto é, o "segundo período" de sua concepção de natureza que envolve, especialmente, os escritos de 1839-1843, como Para a Crítica da Filosofia Hegeliana (Zur Kritik der hegelschen Philosophie) (1839), A Essência do Cristianismo (Das Wesen des Christentums) (1841), Teses Provisórias para uma Reforma da Filosofia (Vorläufige Thesen zur Reform der Philosophie) (1842), Necessidade de uma Reforma da Filosofia (Notwendigkeit einer Veränderung der Philosophie) (1842) e Princípios da Filosofia do Futuro (Grundsätze der Philosophie der Zukunft) (1843).

A palavra "natureza", não no sentido da natureza humana, isto é, não como natureza do homem, do gênero humano, mas, pelo contrário, no sentido da natureza, tal como ela é em si mesma, isto é, no sentido da natureza material, aparece nas obras mencionadas, e isto é visível na obra principal de Feuerbach, A Essência do Cristianismo, muito raramente. Feuerbach não desenvolve aqui nenhuma teoria da natureza, mas a apresenta indiretamente, para defendê-la contra a atitude cristã frente a ela. Por isso, frisa Feuerbach (1971, p. 333): quem é "contra o Cristianismo", é "pela natureza", isto é, quem nega "o Cristianismo", afirma "a natureza". Ele deixa claro que a teologia cristã se relaciona negativamente com a natureza. A depreciação ou desvalorização religiosa da natureza tem consequências para o julgamento da natureza humana, por parte da teologia cristâ, pois esta condena também a dimension natural-sensível da natureza do homem e, em face desta, enaltece o espírito. Esse entendimento negativo do cristão em relação à natureza tornase, por exemplo, mui evidente não só na Doutrina da Criação (Kreationslehre), mas também na Doutrina do Pecado Original (Erbsündeslehre), pois esta, fundada no desdém pela natureza, ampara-se num sentimento de culpa condicionado pela "falha" e "fraqueza" do homem e, por isso, na negação de sua corporeidade, de sua sensibilidade presa à natureza.

Uma confirmação para isso acha-se também, a saber, na circunstância de que o homem deve, de acordo com o entendimento cristão, livrar-se precisamente de sua natureza corporal ("da natureza transgredida"), para merecer e conseguir a "vida eterna", sem as "tentaçôes" e os "desejos da carne". "No céu é o cristão livre daquilo que ele quer ser livre aqui, livre do instinto sexual, livre da matéria, livre da natureza em geral." (FEUERBACH, 1973, p. 551). Precisamente porque a natureza expressa objetividade, necessidade, 
corporeidade, sensibilidade, é ela o negativo, por assim dizer, uma prova dos limites da interioridade, do sentimento religioso, isto é, a barreira concreta que se opõe à illusion de uma existência sobrenatural. Desse ponto de vista cristão, ela deve, portanto, ser eliminada, negada. Feuerbach argumenta que Deus (o todo supremo, a essência sublime), o qual a fantasia religiosa criou, é apenas uma representation fantasmagórica do gênero humano, uma konstruktion subjetiva do homem, abstraída de todas as fronteiras e restriçóes da natureza, e a religião serve ao homem de meio, com o qual ele tenta livrar-se da natureza.

A ausência da natureza em sua obra fundamental pode ser esclarecida da seguinte maneira: ela resulta de sua ocupação com o Cristianismo, que ignora completamente a natureza e póe em seu cume um Deus pessoal, que cria, através do "puro pensar" e do "querer", a natureza, o mundo. Em consequência disso, a natureza foi considerada não enquanto tal; ela não experimenta aqui, na verdade, nenhum tratamento próprio, independente, já que não há no Cristianismo nenhuma autonomia da natureza, nenhuma autarquia e independência dela em relação a Deus. O âmago do Cristianismo não é, então, Deus na natureza, mas, pelo contrário, Deus ilimitado, livre dela e sobre ela; o cristão experimenta, por exemplo, a natureza, a sua necessidade e as suas leis permanentes e contínuas, apenas como barreira insuperável que se opóe, como vimos, à sua pretensão a uma existência imaterial, sobrenatural e transcendente. Mas o homem sem corpo, despojado da matéria, da natureza, é meramente, como pensa Feuerbach, uma personalidade abstrata, um abstraktum, porque apenas a naturalidade, a natureza, garante a essência e a existência do homem como homem, do homem como pessoa.

As reivindicaçôes feuerbachianas de um esclarecimento "natural", "físico" da natureza e, do mesmo modo, de uma conexão do homem com ela apontam para uma crítica abrangente ao Cristianismo, para uma negation fundamental às imaginaçôes e fantasias da teologia cristâ, na qual a natureza não tem nenhum significado positivo. Exatamente como na teologia cristá, a qual subordina a natureza ao querer e ao bel-prazer do homem, também no idealismo, particularmente em Hegel, a natureza está subjugada ao espírito. Hegel acredita que o espírito absoluto se desdobra, se objetiva na natureza, assim, a natureza é também, para ele, não um ser primeiro², autônomo,

${ }^{2}$ Hegel parte náo da natureza, do ser real, sensível, mas do conceito geral do ser, do ser abstrato, pois o ser, com o qual ele começa a sua Ciência da Lógica (Wissenschaft der Logik), é em si mesmo vazio e contém para si nenhum ponto de partida concreto na realidade. O ser, do qual Hegel parte, é "[...] o imediato, o indeterminado, o igual a si mesmo, o idêntico consigo, o sem diferença." (FEUERBACH, 1970, p. 35). 
autárquico, mas algo posto, colocado, como que um outro ser concretizado do espírito. Enquanto a natureza em Hegel é, então, apenas uma outra forma fenomênica do espírito, uma exteriorização ou objetivação dele, Feuerbach a entende, pelo contrário, não como uma degradation da ideia absoluta, nem como o outro eu do eu, o alter ego do ego, mas sim como natura naturans, como o fundamento indeduzível, imediato, incriado, de toda existência real, que existe e consiste por si mesmo.

Contra Hegel, insiste ele, decididamente, nessa position, isto é, na imediaticidade da natureza e da experiência sensível do mundo - e é mister chamar a atenção aqui para isto, a saber, que há, nesse ponto, uma convergência entre Feuerbach e Schelling. Feuerbach -, o antidotum do teísmo e do idealismo pôe a natureza frente ao espírito, pois ele entende por natureza não o puro outro, que só através do espírito foi posto como natureza, entretanto, primeiramente, a realidade material que existe fora e independente do entendimento e é dada ao homem por meio de seus sentidos. Sob essa condição, pode-se conceber a natureza como garantia da exterioridade mesma, como que um existente fora de nós, que nada sabe de si, pois não é para si, mas só em si e por si mesma.

\section{Aproximação e crítica de Feuerbach à religiáo natural}

Partindo desse entendimento acerca da natureza, referir-me-ei, na terceira parte deste trabalho, à "última fase" da concepção de natureza em Ludwig Feuerbach, não só aos escritos fundamentais de 1846-1848, como A Essência da Religiāo (Das Wesen der Religion) (1846), Complementos e Esclarecimentos para a Essência da Religiāo (Ergänzungen und Erläuterungen zum Wesen der Religion) (1846), Preleçôes sobre a Essência da Religiäo (Vorlesungen über das Wesen der Religion) (1848), nos quais Feuerbach, apoiando-se na religiáo da natureza, critica a natureza como objeto da religiáo e a toma como base e fundamento do homem e de todas as coisas, mas também aos seus escritos maduros, como A Pergunta pela Imortalidade sob o ponto de vista da Antropologia (Die Unsterblichkeitsfrage vom Standpunkt der Anthropologie) (1847), A Ciência da Natureza e a Revolução (Die Naturwissenschaft und die Revolution) (1850), O Segredo do Sacrifício ou O Homem é aquilo que come (Das Geheimnis des Opfers oder der Mensch ist, was ißt) (1860), Sobre Espiritualismo e Materialismo (Über Spiritualismus und Materialismus) (1866) e Para uma 
Filosofia Moral (Zur Moralphilosophie) (1868), nos quais ele tenta fundir uma relação fundamental entre filosofia e ciência da natureza.

Se, em A Essência do Cristianismo (Das Wesen des Christentums), o fundamento e, também, o objeto da religião eram ainda a essência moral do homem, abstraída da natureza, quer Feuerbach agora, nesses escritos maduros, superar todo discurso (oratio) antropológico, teleológico ou teológico em relação à natureza, ou seja, obter a separação da mesma da reductio ad hominem, de todos os predicados humanos. Assim, ele fez a si, por tarefa, defender, justificar e fundamentar a autarquia, a autonomia da natureza "contra os esclarecimentos e as deduçóes teológicas" frente a ela. Enquanto ele avaliava a relação cristã em relação à natureza, no todo, negativamente, porque a natureza, no Cristianismo, está submetida arbitrariamente ao afeto religioso, julga ele, agora, a religião da natureza (Naturreligion) parcialmente positiva, já que ela tem por objeto a natureza (o deus físico) e, por isso, ela exerce uma função importante no que diz respeito a uma percepção adequada da natureza.

Não obstante, não se trata, segundo Feuerbach, de maneira nenhuma, de defender a religiáo da natureza em si, embora ela faça valer, de fato, a natureza, na medida em que ela póe, no lugar da humanidade, a natureza. Portanto, ele não está interessado na religião da natureza enquanto tal, mas, unicamente, em sua função estratégica para a sua argumentation contra o Cristianismo e o idealismo, porque ela manifesta a natureza, aponta uma indicação decisiva para "a verdade dos sentidos", demonstra o significado da sensibilidade e atesta o sentimento de finitude do homem e de sua dependência, não de algo sobrenatural, porém, da natureza mesma.

Apesar dessa avaliação parcialmente positiva da religião da natureza, chega Feuerbach, no entanto, à conclusão de que ela não concebe, no fundo, a natureza real, objetiva; pelo contrário, reflete-se também nela apenas a "verdade do homem", pois o homem religioso-natural vê nela não a natureza, como ela é realmente, mas a percebe tão-somente como objeto de sua fé, de sua veneração religiosa, ou de sua imaginação. Porque a natureza oferece ao homem o que ele precisa, foi ela idolatrada como divina; a veneração (Verehrung) ou divinização (Vergötterung) da natureza significa, por conseguinte, a sua "antropomorfização", isto é, a sua "humanização" pela religião, pois o valor, que o homem póe na natureza, é apenas o valor que ele atribui a si mesmo, à sua própria vida. A religiáo da natureza tem, na verdade, por finalidade transformar a essência não sagrada, não humana, da natureza numa essência "sagrada", "personificada". Mas, assim como o panteísmo, Feuerbach a critica, 
precisamente porque ela faz, através dessa transformation, da natureza um Deus. Em oposição a isso, ele não vê a natureza como algo sagrado, divino, isto é, como objeto religioso, tal como ela aparece na religião da natureza, mas, pelo contrário, como uma essência objetiva que existe apenas por si mesma, independentemente do homem. A natureza "[...] é o cerne de todas as forças, coisas e seres sensíveis que o homem distingue de si como não humanas." (FEUERBACH, 1967b, p. 104).

Como justificativa para esse seu procedimento, pelo qual quer livrar a natureza de todas as consideraçóes religiosas e antropológicas, vale a ele que a natureza é o ente que produz tudo de si e por si e, por conseguinte, não deve ser vista como aquilo que ela não é, isto é, 1 . nem como divina (em forma do teísmo), 2. nem como humana (em forma do idealismo). A natureza sempre existiu, quer dizer, ela existe por si e tem seu sentido apenas em si mesma; ela é ela mesma, ou seja, nenhuma essência mística, pois, por detrás dela, não se oculta, nem se esconde, nada humano, nada divino, nenhum absolutum transcendental ou ideal. $\mathrm{O}$ conceito de natureza designa "[...] tudo o que se mostra ao homem, abstraído das sugestôes sobrenaturais da crença teísta, imediatamente, sensivelmente, como base e objeto", isto é, como fundamento e essência, "de sua vida" (FEUERBACH, 1967b, p. 104); trata-se, pois, primeiro daquela essência (luz, ar, água, fogo, plantas, animais etc.), sem a qual o homem não pode nem ser pensado nem existir. A natureza é, assim, a pluralidade de todas as coisas e seres sensíveis que realmente são.

Embora haja, neste ponto, como já mencionado, uma certa concordância entre Feuerbach e Schelling, distancia-se, porém, Feuerbach de Schelling, pois, conforme Feuerbach, a natureza é em si e por si, mas não para si; ela é necessária e regida por leis próprias, sem espírito e sem sujeito, isto é, o independente de toda essência humana ou divina, o indeduzível, o que consiste por si mesmo, por assim dizer, a essência originária, primeira e última. Assim, pode-se dizer que 1. por um lado, a natureza existe per se (em si e por si) e age, em princípio, sem intencionalidade (Absicht), sem querer (Willen) ou saber (Wissen); ela tem seu "entendimento" apenas no entendimento do homem e prova sua essencialidade mediante qualidades, conexôes e relaçóes materiais; 2. todavia, por outro lado, para fazê-la a nós inteligível, é-nos inevitável que devamos empregar sobre ela analogias, expressóes ou conceitos, como totalidade, infinitude, ordem, finalidade, sabedoria etc. Aquilo que o homem acredita reconhecer na natureza como "entendimento", "espírito", 
que empresta a ela uma "teleologia", é, portanto, apenas uma representação humana.

Assim, no que tange a todas as aproximaçóes da natureza, trata-se, para Feuerbach, apenas de conceitos antropológicos, subjetivos, pois, na natureza, tudo acontece sob o fundamento da necessidade e há nela apenas forças, elementos e seres naturais, isto é, leis naturais, às quais a existência humana está submetida. Partindo da necessidade e das leis da natureza, Feuerbach exclui dela todos os critérios humanos ou "efeitos de Deus" para a sua valorização e postula, com isso, a sua autonomia, a sua autarquia. Precisamente esse postulado de Feuerbach em relação ao status da natureza oferece, na situação presente, pontos de referência para uma resistência contra toda exploração arbitrária e brutal da natureza a favor dos desígnios e desejos ilimitados do homem e, ao mesmo tempo, fornece, consequentemente, sugestóes e contribuiçôes para um debate frutífero sobre a crise ecológica atual.

\section{Consideraçóes Finais}

Tendo em vista tais posiçóes, quer Feuerbach fundamentar uma nova relaçáo entre o homem e a natureza, a qual ele vê realizada, em princípio, na dependência do homem em relação à natureza. A natureza é

[...] o que compreende o homem; ela é aquilo cuja aniquilação significa também a própria aniquilação da existência humana; somente através dela consiste o homem, somente dela depende ele em toda a sua atividade, em todos os seus passos. Arrancar o homem da natureza significa o mesmo que separar os olhos da luz, o pulmão do ar, o estômago dos alimentos e querer fazes deles seres existentes por si mesmos. (FEUERBACH, 1967b, p. 91).

Nessa dependência (Abhängigkeit) do homem em relação à natureza, Feuerbach encontra uma clara designação para a natureza como algo não humano e, simultaneamente, como vínculo que liga o homem a ela. O homem não é um ser sem necessidade, ou seja, não é só espiritual (animal rationale), mas, também, simultaneamente, uma essência sensível, física, nascida, por isso, ele é dependente da natureza e precisa dela para seu nascimento, desenvolvimento e autossustento. Ele tem o fundamento de sua vida náo em si, mas, pelo contrário, fora de si e está, portanto, necessariamente, remetido a uma outra essência (à natureza). A dependência do homem da natureza faz da natureza para ele a causa do medo e da insegurança, pois o homem sabe que 
ele sem ela não pode ser. Não obstante, não se deve esquecer que a natureza é também um sistema de leis, "um potencial passivo", frente ao qual o homem pode reagir através da cultura (do desenvolvimento da ciência e da técnica), podendo ser, pois, utilizada por ele a seu favor, embora o essencial da cultura consista nisto, a saber, que ela também se deixe determinar pela "verdade da natureza dos objetos".

Feuerbach vê a cultura realizada preponderantemente nas ciências, e seu entusiasmo para ela e para seu método tinha ele já manifestado nas suas obras Teses Provisórias para a Reforma da Filosofia (Vorläufigen Thesen zur Reform der Philosophie) e Princípios da Filosofia do Futuro (Grundsätzen der Philosophie der Zukunft), nas quais a ligação da filosofia com a ciência da natureza representa para ele uma alternativa à aliança (Allianz) feudal da filosofia com a Teologia e possibilita uma conexão objetiva com a natureza. Nesse empreendimento, Feuerbach almeja que a ciência da natureza sirva de base à sua filosofia, porque ela fornece uma contribuição para a superação, tanto das inconsistências da filosofia especulativa quanto das inconsequências da fantasia e da imaginação religiosas, na medida em que ela, em seu sentido antiteológico e antimetafísico, se ocupa não com objetos arbitrários ou fenômenos sobrenaturais, contudo, exclusivamente, com objetos físico-naturais, atribuindo as suas causas imanentes à natureza. Deve-se aqui chamar a atenção para o fato de que Feuerbach não era nenhum cientista da natureza, porque, de acordo com ele, as ciências da natureza, como a química, a física, a biologia, a botânica, a fisiologia etc., conhecem apenas a "história da natureza", se limitam, com isso, a um elemento isolado da natureza e náo têm, em comparação com a filosofia, nenhum acesso à totalidade da natureza e da alma humana, ou seja, à essência do homem.

Embora Feuerbach esteja convencido de que o homem é uma essência natural e que sua existência, seu nascimento e sua preservação pressuponham a natureza, parece-lhe sem sentido uma ciência ou uma filosofia da natureza separada do homem. Para ele, a natureza é, em princípio, não humana, externa ao homem, mas é, também, esclarecida, conhecida, na medida em que o homem se apropria dela através de seu entendimento. Apesar desses méritos consideráveis, que conferem à concepção de natureza em Feuerbach um essencial avanço frente ao teísmo e ao idealismo, na medida em que ela restitui à natureza o seu valor, ela contém, todavia, "traços especulativos", um caráter "não dialético", "passivo-contemplativo", pois, como se tornou claro na conclusão deste artigo, falta-lhe a dimension social, histórico-concreta. 
Feuerbach considera a natureza parcial e unilateralmente, como uma instância indiferente frente à sociedade, isolada e abstraída de suas condições materiais, sociais e econômicas.

CHAGAS, E. F. The autonomy of nature in Ludwig Feuerbach. Trans/form/ação, Marília, v. 44, n. 3, p. 51-68, Jul./Set., 2021.

\begin{abstract}
This article tries to delineate the proposition that to Feuerbach nature is an autonomous and independent being that comes first in comparison to the spirit. To him, material nature, that exists in its qualitative differentness, independent from thinking, is the original source, the immediate, not deductible, uncreated fundament of all real existence, that exists and consists in itself, when put vis-a-vis the spirit. Feuerbach sets nature against the spirit, for it is his understanding that nature is not a pure other that only through the spirit was set as nature, but as the first source, the objective material reality that exists outside reason and is given to man by means of his senses as fundament and essence of his life. Therefore, one is dealing first with that essence (light, air, water, fire, plants, animals etc) without which man does not exist or could be thought of as existing. To Feuerbach nature is all objects and essences put together. Under this condition it is possible to conceive nature as guarantor of externality itself as if it could exist independently from us, an entity that is unaware of itself and which exists in itself and by itself; for this reason it shall not be seen as something which it is not, i.e., neither divine nor human. Nature always existed, i.e., it exists in itself and has only meaning in itself; it is itself, i.e., it has no mystical essence, it does not hide behind it any absolute being whether human, divine, transcendental or ideal.
\end{abstract}

Keywords: Concept of Nature According to Feuerbach. The Critique of Theism and Idealism. Feuerbach.

\title{
REFERÊNCIAS
}

CHAGAS, Eduardo Ferreira. Projeto de uma nova Filosofia como Afirmacão do Homem em Ludwig Feuerbach. Teoria \& Praxis - Revista de Ciências Humanas e Política, Goiânia, n. 4, p. 31-36, 1992.

CHAGAS, Eduardo Ferreira. A Cisão do Mundo Ético: Lei Divina e Lei Humana na Fenomenologia e na Antígona. Revista de Educacáo e Filosofia, Uberlândia, n. 15, p. 67-74, 1994.

CHAGAS, Eduardo Ferreira. Religião: O homem como imagem de Deus ou Deus como imagem do homem? in: OLINDA, Ercília Maria Braga de. (org.). Formaçáo Humana: Liberdade e Historicidade. Fortaleza: EDUFC, 2004. 
CHAGAS, Eduardo Ferreira. Natureza e Liberdade em Feuerbach e Marx. Campinas: Phi, 2016.

CHAGAS, Eduardo Ferreira; OLIVEIRA, Renato Almeida de. Consciência, Natureza e Crítica Social em Hegel, Feuerbach e Marx. Porto Alegre: Editora FI, 2019, 305 p. ISBN: 978-85-5696-519-6. Disponível em: https://www.editorafi.org/519hegel. Acesso em: 21 de jun. 2018.

CHAGAS, Eduardo Ferreira; REDYSON, Deyve. Ludwig Fuerbach: filosofia, religião e natureza. São Leopoldo: Nova Harmonia, 2011.

CHAGAS, Eduardo Ferreira; REDYSON, Deyve; PAULA, Marcio G. de. Homem e Natureza em Ludwig Feuerbach. Fortaleza: Ediçóes UFC, 2009. (Série Filosofia, no 8).

CORNEHL, Peter. Feuerbach und die Naturphilosophie. Zur Genese der Anthropologie und Religonskritik des jungen Feuerbach. Neue Zeitschrift für systematische Theologie und Religionsphilosophie, Berlim, n. 11, p. 37-93, 1969.

FEUERBACH, Ludwig. Ludwig Feuerbach in seinem Briefwechsel und Nachlass sowie in seiner philosophischen Charakterentwicklung. Hrsg. v. K. Grün, 2 Bde. Leipzig/Heidelber, 1874.

FEUERBACH, Ludwig. Gesammelte Werke. Berlim: Akademie, 1967a.

FEUERBACH, Ludwig. Pierre Bayle. Ein Beitrag zur Geschichte der Philosophie und Menschheit (1838). Berlim: Akademie, 1967b.

FEUERBACH, Ludwig. Vorlesungen über das Wesen der Religion (1851). Nebst Zusätzen und Anmerkungen. Berlim: Akademie, 1967c.

FEUERBACH, Ludwig. Geschichte der neuern Philosophie von Bacon von Verulam bis Benedikt Spinoza (1833). Berlim: Akademie, 1969a.

FEUERBACH, Ludwig. Geschichte der neuern Philosophie. Darstellung, Entwicklung und Kritik der Leibnizschen Philosophie (1837). Berlim: Akademie, 1969 b.

FEUERBACH, Ludwig. Theogonie nach den Quellen des klassischen, hebräischen und christlichen Altertums (1857). Berlim: Akademie, 1969c.

FEUERBACH, Ludwig. Kleinere Schriften I (1835-1839). Berlim: Akademie,1969d.

FEUERBACH, Ludwig. Das Wesen des Christesntums (1841), Berlim: Akademie, 1973.

FEUERBACH, Ludwig. Kleinere Schriften II (1839-1846), Zur Kritik der Hegelschen Philosophie. Berlim: Akademie, 1970.

FEUERBACH, Ludwig. Kleinere Schriften III (1846-1850), Uber das Wesen der Religion in Beziehung auf R. Hayms, Feuerbach und die Philosophie. Berlim: Akademie, 1971.

FEUERBACH, Ludwig. Kleinere Schriften III (1851-1866). Berlim: Akademie, 1972. 
FEUERBACH, Ludwig. Vorlesungen über die Geschichte der neueren Philosophie (Von G. Bruno bis G. W. F. Hegel, Erlangen 1835-1836), bearb. v. C. Ascheri u. E. Thies. Darmstadt, 1974.

FEUERBACH, Ludwig. Briefwechsel I (1817-1839). Berlim: Akademie, 1984.

FEUERBACH, Ludwig. Briefwechsel II (1840-1844). Berlim: Akademie, 1988.

FEUERBACH, Ludwig. Paul Johann Anselm Ritter von Feuerbachs Leben und Wirken (1852f.), Berlim: Akademie, 1989.

FEUERBACH, Ludwig. Briefwechsel III (1845-1852). Berlim: Akademie, 1993.

FEUERBACH, Ludwig. Briefwechsel IV (1853-1861). Berlim: Akademie, 1996a.

FEUERBACH, Ludwig. Entwürfe zu einer Neuen Philosophie. Hsg. v. W. Jaeschke u. W. Schuffenhauer, Hamburg, 1996 b.

FEUERBACH, Ludwig. Einleitung in die Logik und Metaphysik (Erlangen 18291830), bearb. v. C. Ascheri u. E. Thies, Darmstadt, 1975.

FEUERBACH, Ludwig. Vorlesungen über Logik und Metaphysik (Erlangen 18301831), bearb. v. C. Ascheri u. E. Thies, Darmstadt, 1976.

FEUERBACH, Ludwig. Frühe Schriften, Kritiken und Reflexionen (1828-1834). Berlim: Akademie, 2000.

HÖPPNER, Joachim. Ludwig Feuerbach und seine materialistische Weltanschauung in ihrer historischen Bedeutung für die wissenschaftliche Philosophie. Phil. Diss. Leipzig, 1960.

HÜSSER, Heinz. Natur und Religion in der Religionskritik Ludwig Feuerbachs. Betrachtungen zu einem aktuellen Problem. In: Ludwig Feuerbach und die Philosophie der Zukunft. Hrsg. v. H.-J. Braun. Berlim: 1989. p. 39-54.

HÜSSER, Heinz. Natur ohne Gott. Aspekte und Probleme von Ludwig Feuerbachs Naturverständnis. Würzburg: Verlag, 1993.

HÜSSER, Heinz. Die Menschwerdung der Natur. In: Solidarität oder Egoismus. Studien zu einer Ethik bei und nach Ludwig Feuerbach. Hrsg. v. H.-J. Braun. Berlim, 1994. p. 141-153.

JESSIN, I. M.: Die materialistische Philosophie Ludwig Feuerbachs. Berlim: Dietz, 1956.

JODL, Friedrich. Ludwig Feuerbach. Stuttgart: F. Frommanns (H. Kurtz), 1904.

LEY, Hermann. Ludwig Feuerbach über das Bündnis von Philosophie und Naturwissenschaft und der dialektische Materialismus. In: Referenten konferenz der zentralen Kommission Wissenschaft. Berlim: Deutscher Kulturbund, 1972. p. 70-78. 
LEY, Hermann. Ludwig Feuerbach und die Natur. In: Atheismus in der Diskussion. Kontroversen um Ludwig Feuerbach. Hrsg. v. H. Lübbe u. H.-M. Saß, M. München: Kaiser, 1975. p. 120-141.

MÜNZ, Theodor: Spinoza, Feuerbach und die Würde der Natur. In: Ludwig Feuerbach und die Philosophie der Zukunft. Hrsg. v. .H.-J. Brau, H.-M. Sass, W. Schuffenhauer und F. Tomasoni. Berlim, 1989. p. 55-67.

REITEMEYER, Ursula. Philosophie der Leiblichkeit. Ludwig Feuerbachs Entwurf einer Philosophie der Zukunft. Frankfurt Am Main.: Suhrkamp, 1988.

SCHMIDT, Alfred. Emanzipatorische Sinnlichkeit. Ludwig Feuerbachs anthropologischer Materialismus. München: C. Hanser, 1973.

SCHRÖTER, Gisela. Zum Bündnis von Philosophie und Naturwissenschaft im Materialismus Ludwig Feuerbachs. Deutsche Zeitschrift für Philosophie, Heft 36, Jahrgang, Berlim, p. 28-36, 1988.

SCHUFFENHAUER, Werner. Ludwig Feuerbach und der junge Marx. Zur Entstehungsgeschichte der marxistischen Weltanschauung. Berlim: Deutsche Verlag der Wissenschaften, 1965.

SOUZA, Draiton de. Zur Ethik Ludwig Feurbachs. Göttingen: Cuvillier Verlag Göttingen, 1998. p. 55-93.

STEINDL, Regina. Bemerkungen zum Naturbegriff bei Ludwig Feuerbach. In: Wissenschaftliche Reihe, Jena, 34, H. 3, p. 361-366, 1985.

TOMASONI, Francesco. Ludwig Feuerbach e la natura non uman: riconstruzione genetica dell'Essenza della religione, con pubblicazione degli inediti. Firenze: La Nuova Italia, 1986.

TOMASONI, Francesco. Ludwig Feuerbach. Biografia intellettuale. Brescia: Morcelliana, 2011.

Recebido: $10 / 3 / 2019$

Aceito: 28/5/2020 